\title{
NŪDO SHASHIN: LA CONSTRUCCIÓN DEL DESNUDO FEMENINO \\ EN LA FOTOGRAFÍA DEL PERIODO MEIJI
}

\section{María Ibarí Ortega}

ibari77@gmail.com

Centro de Estudios de Asia y África - El Colegio de México

Recibido: 28-02-2013

Aceptado: 14-03-2013

\section{Resumen}

En este texto examinaré los retratos fotográficos de desnudos femeninos de la colección privada de Ishiguro Keishō, producidos en Japón durante el periodo Meiji (1868-1912), para analizar la forma en que se visualizó el cuerpo femenino bajo los discursos modernos producidos en torno a la sexualidad, la re-significación de lo erótico y la distinción de género, durante el complejo proceso de modernización que se generó en Japón durante la segunda mitad del siglo XIX.

Palabras Clave: pornografía, fotografía, género, sexología, modernidad, sexualidad, Japón.

\begin{abstract}
In this text I will examine photographs of nude Japanese woman from the private collection of Ishiguro Keishō, produced in Japan during the Meiji Period (1868-1912), to analyze the multiple forms of viualization of the female body under the modern discourses about sexuality, the resignification of the erotic, and gender distinction, during the complex process of modernization that took place in Japan in the second half of the XIX century.
\end{abstract}

Keywords: pornography, photography, gender, sexology, modernity, sexuality, Japan. 


\section{Introducción}

En este texto examinaré los retratos fotográficos de desnudos femeninos de la colección privada de Ishiguro Keishō, ${ }^{1}$ situándolos dentro de un contexto histórico, ideológico, y cultural caracterizado por un cambio en la mirada, asociada a la nueva consciencia que sobre la sexualidad y el cuerpo se había comenzado a promover como parte del proceso de modernización de Japón. Durante este periodo se adoptó, interpretó, e interiorizó el ideal occidental de "civilización" (kaika), sobre el cual se construyeron gran parte de los discursos nacionales modernos. Al buscar publicaciones sobre los inicios de la fotografía erótica durante el periodo Meiji (1868-1912)2 ${ }^{2}$, me di cuenta de que la historia de nüdo shashin (literalmente fotografía de desnudos) ha sido ignorada en la producción académica dedicada a la historia de la fotografía en japón. Lo poco que se ha escrito sobre los orígenes de éste género literario proviene de tres coleccionistas privados: Hoshino Chōichi, Shimokawa Kōshi e Ishiguro Keishō̄ . Estos individuos han activado la memoria histórica en torno a la economía libidinal moderna del periodo Meiji, al arrojar luz sobre los contenidos visuales de sus colecciones de nūdo shashin, convertidas en complejos objetos del deseo. Con economía libidinal me refiero a la intensificación de las relaciones e intercambios entre las condiciones materiales (y visuales), los modos de producción del deseo (y de sujetos deseantes), el conocimiento producido en torno a la sexualidad, y la conformación de una moral colectiva. Dentro de la economía libidinal todas estas relaciones e intercambios se establecen y transforman dentro de una estructura ideológica y social históricamente determinada ${ }^{4}$.

\footnotetext{
${ }^{1}$ Los nombres personales en japonés están escritos en el orden apellido-nombre.

${ }^{2}$ Agradezco a Ishiguro Keishō el haberme permitido trabajar su colección fotográfica durante mi estancia de investigación en el verano del 2010 en la Maestría en Estudios de Asia y África del Colegio de México, realizada gracias al apoyo de Fundación Japón . Esta colección ha motivado mi investigación en torno a la conformación de una consciencia sexual moderna y sus formas de visualización en Japón durante la segunta mitad del siglo XIX.

${ }^{3} \mathrm{He}$ consultado para esta tesis los tres catálogos publicados en Japón de fotografías de desnudos femeninos datadas en el periodo Meiji (1868-1912) por los tres coleccionistas privados Hoshino Chōichi, Shimokawa Kōshi y Ishiguro Keishō. El trabajo de Ishiguro sobresale en contenidos y análisis de la imágen si lo comparamos con los dos libros publicados por Hoshino y Shimokawa. De éstos dos últimos, el primero sólo contiene las imágenes que comprenden su colección, mientras que el segundo se centra más en imágenes de medio denudo conocidas como Yokohama Shashin, principalmente en la colección de Edward S. Morse. Sin embargo, en el catálogo publicado por Shimokawa hay una explicación in extenso sobre la producción de nūdo shashin durante la guerra ruso-japonesa (1904-1905) (Hoshino, 1970; Kōshi, 1995; Keishō, 1996; Keishō, 2002).

${ }^{4}$ El término ha sido definido por Francis Lyotard al analizar las mutuas imbricaciones que establecen lo social y lo libidinal, la ley y el deseo. Lyotard identifica una asociación intrínseca entre el orden del discurso y el deseo, de donde se produce lo represivo así como la liberación. Según este autor, todos los sistemas políticos y sociales negocian entre sí a partir de redes de deseo y discurso. En su libro Aconomie libidinale publicado en 1974, Lyotard describe el capital como una estructura social que comparte similitudes con el inconsciente a tal grado que su función es modular y moderar, reprimir y explotar energías libidinales. Al identificar su pensamiento con la teoría psicoanalítica de Freud y al desarrollar su
} 
Antes de introducir los ejemplos seleccionados de nūdo shashin de la colección de Ishiguro Keishō, introduciré de manera breve la forma en que el conocimiento moderno occidental impactó en el pensamiento intelectual y en los discursos generados en torno a los usos y costumbres, así como a la moral pública en Japón durante la segunda mitad del siglo XIX ${ }^{5}$. Considero que la aparición de nuevas representaciones sexuales a partir de nuevas tecnologías visuales como la fotografía, jugó un papel determinante en la fabricación e interiorización de una nueva norma sexual "civilizada," "heterosexual," y en cierta medida "occidentalizada".

\section{Epistemologìa moderna y distinción de género en el periodo Meiji}

Durante este periodo se publicaron varios libros sobre teorías en torno al "mejoramiento" o "reforma" de los usos y costumbres" o füzoku kairyōron, como el de Masataka Dohi titulado Nihon füzoku kairyōron". Estos textos respondían al proyecto nacional del gobierno Meiji, el cual buscaba reforzar los fundamentos nacionales modernos a partir de la transformación de la mentalidad y el comportamiento de los individuos. Bajo la luz de esta nueva literatura las costumbres o füzoku se dividían en

crítica sobre el pensamiento marxista, argumenta que es en el plano consciente donde se articulan la "razón, el orden, la lógica, y la aceptación social para controlar los impulsos biológicos considerados potencialmente peligrosos, aunque no se controlen totalmente. Lyotard identifica una operación comparable al deseo y los impulsos instintivos en el capitalismo. Así como la mente consciente reprime los impulsos ingobernables, la estructura del capitalismo 'disimula' las intensidades impulsivas libidinales, de tal modo que las estructuras conceptuales ocultan efectos que por su pura intensidad o exceso disimulan o encubren las estructuras internas propias. El capital controla energía inestable a través de una circulación sistemática de producción y distribución, consumo e intercambio. Según este autor el capitalismo es mantenido por las intensidades libidinales irracionales que existen para regular y excluir, y lo hace a través del valor de intercambio, o sea, el valor de una mercancía a partir de su intercambio; (Lyotard, 2004).

${ }^{5}$ El término füzoku proviene de China como parte del canon confuciano. Como lo explica Suzanne O’brien, en Los Analectos, texto que recoge las máximas, preceptos y parábolas de filósofo Chino Confucio (604-531 A.D.C.), se menciona que "la esencia del caballero es la del viento $(f \bar{u})$ : la esencia de la gente pequeña (común) es la del pasto. Cuando el viento pasa sobre pasto, este no puede más que doblarse". El sentido ético de füzoku adoptado por el gobierno Tokugawa (1603-1868), toma la re-definición del término del filósofo Xun Zi (ca- 298-238 A.C.), según indica O’Brien, en la que el viento $(f \bar{u})$ reforma a la gente común $(z o k u)$ como una causa natural. Esta idea de reforma significaba "influenciar y cambiar las costumbres" y se adoptó de manera directa en las concepciones confucianas de "buen gobierno" y la del "gobernante virtuoso" asociándolas a la palabra füzoku. En el primer artículo de la versión de 1630 de las "Leyes para las Casas Militares" (Buke shohatto) se les ordenaba a los samuráis "cultivar las artes militares, hacer una moralidad humana clara, y un correcto füzoku; (O'brien: 2007: 2 y 3).

${ }^{6}$ Otros títulos similares fueron publicados en esa época sobre el "mejoramiento" de las costumbres. Estos textos respondieron a la conformación de un nuevo pensamiento (shin shisō), el cual se intentaba promover a nivel nacional. Masataka Dohi, originario de la prefectura de Okayama, comenzó una organización local conocida como Dainippon füzoku kairyō kukai que para 1889 tenía alrededor de quince sedes en diferentes provincias y alrededor de 8,700 miembros difundiendo esta teoría a nivel nacional, según anunció el periódico Shinonome shimbun en marzo de ese mismo año (Ogi, 1990: 40). 
"barbáricas" (yaban) o "civilizadas" (bunmeika), diseminando ideas que alabaran los principios de "civilización e ilustración" (bunmei kaika) con el fin de cambiar la mentalidad de la gente. Se buscaba que las personas "incorporaran" o "interiorizaran" (torikomare) en sus hábitos cotidianos dichos principios para "auto-regularse" y "autocontrolarse" (jiko-kisei), dirigiendo especial atención al comportamiento sexual ${ }^{7}$.

Al analizar las repercusiones de la fotográfica en la producción de un cuerpo moderno en Meiji, específicamente la construcción del desnudo como objeto erótico en la producción de nūdo shashin durante este periodo histórico, me referiré principalmente a la creación de un cuerpo imaginario construido artificialmente desde la representación. El cuerpo en la producción fotográfica comercial de Meiji se construyó principalmente a partir de dos discursos; uno que reflejaba la modernidad a través de la transformación de la apariencia, y otro que mostraba al cuerpo dentro de escenarios "tradicionales" como parte de las costumbres y la vida cotidiana convertidas en suvenir para extranjeros. Para referirme a la esfera de la representación fotográfica considero necesario esbozar las coordenadas ideológicas y dispositivos que dieron sentido a la emergencia de nuevas formas de representación del cuerpo, convertido en un complejo soporte donde se encarnaba tanto la modernidad y como la tradición, y que en el caso de nüdo shashin la sexualidad se comenzó a visualizar de manera directa a través de la desnudes femenina, exhibiendo el cuerpo de la mujer japonesa recortado del acto sexual. El aparataje ideológico instaurado en Meiji se conformó a partir de un conjunto de leyes e instituciones, así como de la producción visual que estas instancias legitimaron en la producción de nuevos discursos sobre género, sexualidad, y estatus social en los que el cuerpo funcionó como el medio para visibilizar los ideales e imaginarios civilizatorios modernos. El nuevo aparataje ideológico y el conjunto de instituciones producidas en manos de los burócratas y políticos del nuevo estado moderno japonés pueden describirse como lo que Michael Foucault denominó microfísica del poder. El concepto de poder en el pensamiento Foucaultiano tiene una relación directa en la construcción del cuerpo y el sujeto en sociedades occidentales industrializadas, al definir tanto al cuerpo como al sujeto por medio de relaciones de poder no exclusivas de aquellos que lo poseen. Según la definición de Foucault, el poder es una propiedad que no se aplica pura y simplemente como una obligación o una prohibición sobre aquellos que no lo tienen (Foucault, 1998). El poder es una propiedad que invade a los individuos, pasa por ellos, los atraviesa, y se apoya sobre ellos dando forma a las relaciones que establecen entre ellos. El conocimiento que se genera a partir de estas relaciones cobra formas específicas de poder, por lo que Foucault identifica una asociación inseparable entre poder y saber. De tal forma "el sujeto que conoce, los objetos que conoce y las modalidades del conocimiento" (Foucault, 1998; 34), no son más que efectos de las implicaciones de las relaciones de poder las cuales se modifican como parte de las transformaciones históricas.

\footnotetext{
${ }^{7}$ Véase: (Ogi, 1990: 40).
} 
Las relaciones de poder que dieron forma a los cuerpos modernos en Meiji también pueden analizarse de acuerdo con esta definición, al articularse bajo una serie de engranajes complejos no unívocos sobre la producción de un saber "verídico" en torno al cuerpo y la identidad sexual de los sujetos; a la vez que permiten identificar determinadas continuidades en sus manifestaciones a partir de la regulación de prácticas existentes. Las formas que moldearon las relaciones de poder bajo los discursos médico-legales modernos en torno al cuerpo, la sexualidad, y el género, respondieron principalmente a los intereses del estado japonés a través de las tecnologías del poder-saber. Como parte de estas tecnologías políticas del cuerpo moderno en el periodo Meiji, la construcción, difusión, comercialización y consumo del nuevo saber sobre el cuerpo tuvo un papel determinante en la auto-disciplina e internalización del conocimiento, y su impacto en la nueva consciencia moderna sobre la distinción de género a partir de su visualización.

Para comprender los mecanismos que articularon la imagen como medio de representación visual del cuerpo moderno, el cuerpo como imagen, y su instrumentalización en la "invención" del desnudo y del deseo sexual heterosexual en Meiji, es importante contextualizar la relación que se estableció entre la imagen, la mirada, y los discursos hegemónicos en torno al cuerpo durante este complejo periodo histórico en Japón. Durante el periodo Meiji, la distinción de género se comenzó a visualizar a partir de las bases biológicas y científicas por medio de las ilustraciones médicas anatómicas de los órganos sexuales, produciendo una nueva forma de mirar y racionalizar el cuerpo a partir de la introducción de manuales sobre sexología ilustrados a mediados del siglo XIX en Japón.

A diferencia de los primeros textos sobre anatomía traducidos desde el siglo XVIII como el famoso Kaitai shinsho (Nuevo tratado sobre anatomía) publicado en 1775 y traducido por los médicos rangaku Maeno Ryotaku y Sugita Genpaku (Bowman Janetta, 2007), la visualización anatómica en el periodo Meiji marcó una clara distinción de género al representar de manera gráfica los órganos reproductivos masculino y femenino. El texto que más impacto tuvo durante el periodo de la Restauración Meiji fue The Book of Nature, escrito por el médico norteamericano James Ashton, y traducido al japonés por Chiba Shigeru en 1873 (Kobayashi, 2008) bajo el título Zōkakiron (Teoría de la máquina creadora). Este libro ofrecía información e ilustraciones didácticas sobre el acto sexual y la reproducción humana sobre una base ginecológica, incluyendo métodos de contracepción y aborto ${ }^{8}$. Este tipo de literatura ilustrada sobre sexología anatómica tuvo mucho éxito al circular como publicaciones periódicas de divulgación popular conocidas como Zōkakiron o Teorías sobre la máquina creadora (Figuras 1 y 2). Los diagramas anatómicos y descripciones técnicas de los órganos reproductivos que se incluían en estas publicaciones populares introdujeron a las masas una nueva referencia visual para comprender las diferencias de género y las distinciones entre las funciones sexuales de hombres y mujeres (Reichert, 2006).

\footnotetext{
${ }^{8}$ The Book of Nature fue publicado en 1861, 1865, 1870 y la más reciente en 1974 (Silver-Isenstadt, 2002). Sobre los contenidos de estos textos en idioma inglés consultar Marran (2007); la versión original del periodo Meiji fue publicada en la recopilación de textos sobre füzoku/sei (Ueno; Ogi e Isao, 1990).
} 
Figuras 1 y 2. Ilustraciónes del libro Danjo jiei zōkaki shinron (Nueva teoría de la máquina creadora y la autopreservación de hombres y mujeres), publicado por Mutō Tadao en 1895.
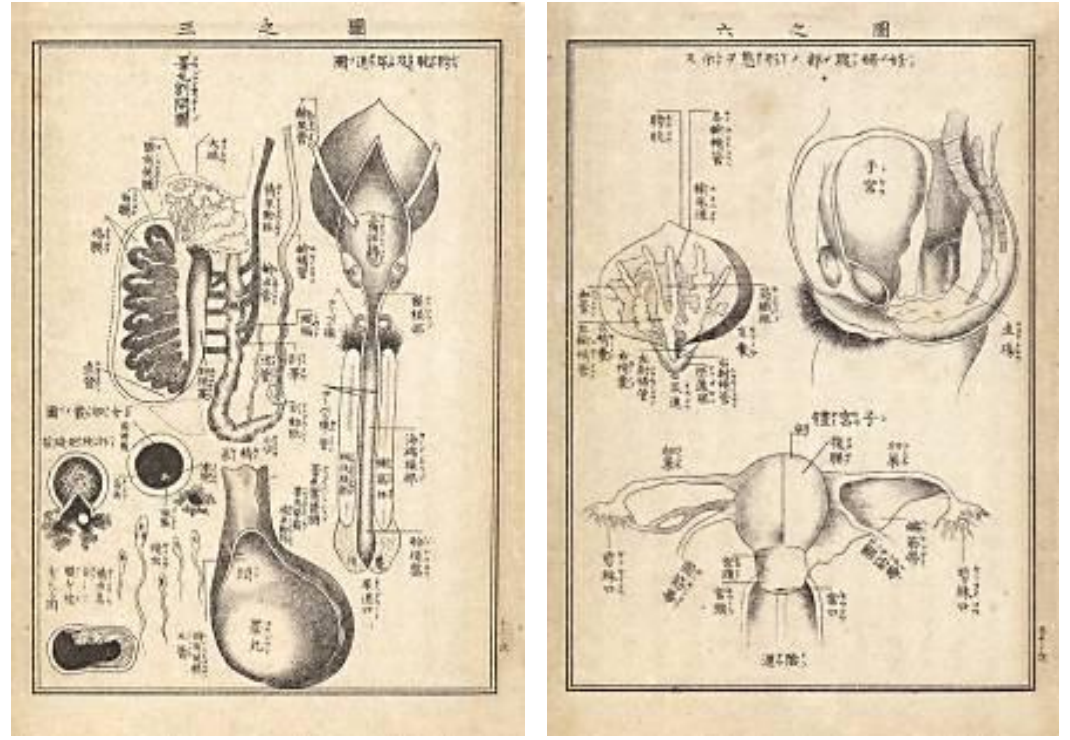

Fuente: Mutō Tadao (1895): Danjo jiei zōkaki shinron.

Acervo de la Biblioteca de la Universidad de Doshisha.

Dado que el objetivo de las regulaciones sexuales de Meiji era el reforzar la unión "natural" heterosexual entre hombres y mujeres las leyes sobre "la creación" ( $z \bar{o} k a)$ y la higiene del cuerpo (eisei) se alinearon perfectamente con la "moral civilizada" de Meiji, construyendo todo un discurso comercializado en torno a los "órganos creadores" (zōkaki), término que ya existía anteriormente y que sirvió para seguir refiriéndose al sistema reproductivo humano. Sin embargo, en Japón existía un extenso canon sobre las representaciones visuales de los órganos genitales desde el periodo Edo en los grabados eróticos shunga (imágenes de primavera) ${ }^{9}$. Por un lado, la representación del cuerpo en este tipo de imágenes populares sexualmente explícitas se centraba principalmente en los genitales para diferenciar los cuerpos de los hombres y mujeres representados en diferentes posturas sexuales con los órganos sexuales agigantados, centrando la atención del espectador sobre ellos. Algunos elementos iconográficos del shunga (imágenes de primavera) también se podrán identificar en la producción de la fotografía erótica nūdo shashin, sin embargo, la fotografía erótica producida en Meiji ofrecerá al espectador un heterogéneo y ecléctico catálogo con diversos elementos, posturas y poses que nos remitirán también a la representación del desnudo femenino producido en la pintura estilo occidental yōga. De esta forma, ciencia, arte, erotismo, y pornografía constituirán las capas semánticas e iconográficas de nūdo shashin.

\footnotetext{
${ }^{9}$ Sobre las regulaciones, estrategias de subversión, y el papel de los agentes editoriales frente a las regulaciones y prohibiciones de la estampa erótica shunga durante el periodo Tokugawa Amaury García ha desarrollado una profunda investigación (García, 2011).
} 
Desde este trasfondo histórico-ideológico deseo introducir las imágenes conocidas como nūdo $\operatorname{shashin}^{10}$, ya que considero que estas imágenes participaron directa o indirectamente dentro del proceso de auto-regulación y auto-domesticación del deseo sexual en este periodo en Japón. La nueva norma sexual dominante buscaba consiolidar un ideal de masculinidadmoderno, civilizado y compulsivamente heterosexual, mientras que la sexualidad femenina se comenzó a redefinir a partir del discurso médico-sexológico como una máquina reproductiva, por un lado, o como excesivo y anormal, por el otro.

\section{Nūdo shashin: La colección de Ishiguro Keishō}

Las imágenes producidas bajo la categoría de nüdo shashin fueron impresas en masa en tamaño meishiban o carta-de-visite, originalmente para el consumo local. De acuerdo con Ishiguro Keishō, nūdo shashin se distingue de las representaciones de mujeres japonesas semidesnudas producidas como suvenir bajo la categoría de Yokohama shashin, al exhibir de manera explícita los genitales femeninos dentro de escenarios híbridos muy particulares. Por otro lado, se puede identificar una notable diferencia entre estas imágenes ya que en la producción de Yokohama shashin el color aplicado sobre las impresiones fotográficas era un elemento importante, y en la mayoría de las impresiones de nüdo shashin carecen de pigmentación alguna; además ésta última categoría se caracteriza por utilizar diferentes objetos, muebles, y artefactos modernos occidentales para escenificar la exhibición del denudo femenino.

A diferencia de la producción comercial de Yokohama shashin, los fotógrafos japoneses de $n \bar{u}$ do shashin no estaban interesados en la fabricación de interiores "tradicionales" recreados en estudios, más bien, comenzaron a producir escenarios eclécticos y heterogéneos donde el cuerpo femenino se re-configuraba en espacios ambiguos y un tanto descuidados.

Dentro de esta colección, en particular siete imágenes producidas como negativos de colodión húmedo (shippan), impresas sobre papel albúmina, han sido identificadas por el coleccionista como las fotografías más antiguas de desnudos en Japón ${ }^{11}$. A pesar de que la técnica de impresión del colodión húmedo se introdujo por primera vez en Japón entre 1853 y

$10 \mathrm{Al}$ revisar los usos de la palabra $n \bar{u} d o$, podemos tener una idea aproximada del momento en que se comienza a nombrar con éste término a la producción de fotografías de mujeres desnudas del periodo Meiji. Es probable que la palabra $n \bar{u} d o$ fuera traducida del inglés nude o del francés nие o $n и$; según Yū Kawai, la palabra nūdo fue introducida del inglés al japonés primero como niyūdo -escrita con katakanatal como se incluyó en el Modan yōgo jiten (Diccionario de términos modernos) publicado en 1930. Posteriormente, se encontrará escrita como nüdo en artículos de periódicos a partir de 1950, (Kawai, 2010)

${ }^{11}$ No puedo afirmar que las primeras fotografías de desnudo en Japón fueran producidas desde los años 1870's, pero al datarse según el periodo en que el colodión húmedo se introdujo en Japón, Ishiguro aproxima su datación durante estos años (Keishō, 2002). 
1862, estos primeros retratos nūdo shashin han sido datados por Ishiguro en $1877^{12}$. Con el proceso del colodión húmedo (shippan) el tiempo de exposición mejoró significativamente a comparación de los daguerrotipos $^{13}$, permitiendo ahora reproducir varias copias. Sin embargo, estos negativos tardaban un minuto para capturar la imagen de la persona retratada, por lo que las posturas siguen siendo rígidas en los primeros retratos, como en el caso del retrato de una mujer desnuda situada en una silla occidental (Figura 3). Sus ojos están cerrados y su torso parece más una escultura que un cuerpo con vida, dando la impresión de estar frente a un fantasma.

En otra imagen impresa con un negativo de colodión húmedo, una mujer posa parada inexpresiva cubriendo su cuerpo con un kimono abierto en la parte frontal revelando sólo la parte inferior de su cuerpo (Figura 4). Ishiguro Keishō ha atribuido estas dos imágenes a Yokohama Matsusaburō.

Con la introducción de la tecnología de negativos o placa seca o kanpan en 1880 en Japón, se mejoraron aún más los tiempos de exposición y la fotografía se comenzó a comercializar en masa, permitiendo la re-producción de un número ilimitado de copias a partir de una misma imagen, así como la emergencia y proliferación de fotógrafos amateur. A partir de este cambio tecnológico los gestos y la corporalidad de los sujetos que se muestran en el resto de las carte de visite representan un cambio radical (Kinoshita, 2003). Esto permitió retratar poses más dinámicas así como la serialización de la imagen. Como Naoyuki Kinoshita ha señalado, con la introducción de la tecnología de placa seca

\footnotetext{
${ }^{12}$ Siguiendo el argumento de Bonnel D. Robinson sobre el contexto de la fotografía de Meiji, algunos de los primeros negativos producidos con la tecnología de la placa-húmeda (técnica también conocida como colodión) en Japón, se han datado aproximadamente desde 1853. Esta técnica fotográfica fue inventada en 1851 por Frederick Scott Archer, y consistía en aplicar una emulsión viscosa sobre una placa de vidrio la cual debía permanecer húmeda durante el proceso de exposición y revelado para alcanzar una densidad homogénea en el negativo. Con el colodión o placa húmeda se podían reproducir un gran número de impresiones del mismo negativo, impresas en su mayoría sobre el papel cubierto de una emulsión producida con huevo (albúmina). Esta forma de impresión fue inventada en 1850 por Louis Désiré y se caracteriza por tener una superficie brillante sin granulado producida con una capa delgada de emulsión a base de clara de huevo. Estas técnicas (colodión húmedo y la impresión en albúmina) revolucionaron la reproductibilidad fotográfica en Japón, al contribuir considerablemente con la producción y circulación de imágenes mercancía en el mundo, dando un giro radical de la técnica del daguerrotipo (imágenes únicas fijas sobre placas de metal), a la "fotografía comercial producida en masa" (Robinson, 1988: 43). El historiador de arte Kinoshita Naoyuki ha identificado a Hikoma Ueno como uno de los pioneros en publicar manuales fotográficos describiendo la técnica del colodión húmedo en Japón, diseminado en su texto de 1862 titulado Seimikyoku hikkei (Chemist's Handbook, 3 vols.), en el que incluyó una descripción detallada del proceso de este tipo de negativo. Con el tiempo las investigaciones sobre las técnicas fotográficas incrementaron en Japón, y en 1867 Yanagawa Shunsan, proveniente del dominio de Owari, publicó el primer manual dedicado en su totalidad a la técnica del colodión húmedo en su manual Sahshinkyō zusetsu (Técnicas Ilustradas de Fotografía); citado por Naoyuki (2003).

${ }^{13}$ Philipp March y Claudia Delank afirman que el termino in'eikyō fue usado originalmente para denominar al daguerrotipo en lugar de ginpan (placa de plata), y que la autora traduce como "espejos estampados", al explicar que in significa "estampar" o "imprimir", ei o kagare "sombra", "reflejo" o "figura", y kyo o kagami "espejo". Finalmente deduce que el daguerrotipo fue comprendido en Japón fue como un nuevo medio en el que se "imprimían" figuras o retratos (March y Delank, 2002: 8).
} 
en Japón nuevos eventos ahora podían ser capturados, como las erupciones volcánicas y los terremotos. Junto con todos estos nuevos temas fotográficos, el cuerpo desnudo femenino se reprodujo sistemáticamente en masa dentro de una cultura visual basada en el realismo fotográfico, favoreciendo la ilusión de proximidad con lo fotografiado ${ }^{14}$.

Aunque los muebles occidentales eran caros en ese momento varios artefactos extranjeros fueron introducidos como el atrezzo de la fotografía de nüdo shashin, incluidos los telones de fondo y los tapetes, para hacer la exhibición del cuerpo "tradicional" de la mujer japonesa más atractivo para los japoneses, fascinados con el estilo y la sofisticación occidental (haikara). Como resultado, el espectáculo visual del cuerpo femenino sexualizado en nūdo shashin participó en el complejo proceso de hibridación cultural que caracterizó a este período histórico en Japón.

Figuras 3 y 4. Yokohama Matsusaburō colodión húmedo albumina carte de visite 62 x $104 \mathrm{~mm} 1877 \mathrm{ca}$.
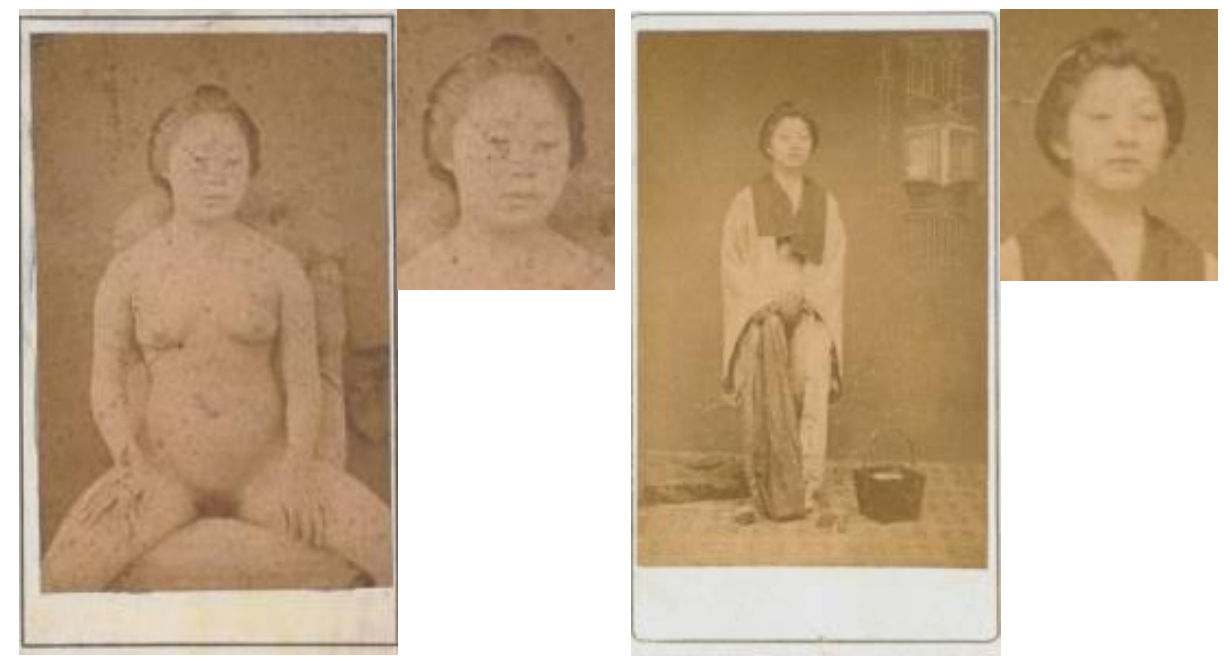

Fuente: Colección Ishiguro Keishō.

La naturaleza híbrida de nūdo shashin no se caracteriza por constituir una taxonomía de cuerpos homogénea; hay ejemplos donde el cuerpo de la mujer japon esa se muestra con una fisionomía más estilizada recurriendo a modelos con corporalidades más "occidentalizadas", posando en habitaciones tradicionales japonesas decoradas con fusuma y biombos, mientras que en otros casos se puede distinguir fisionomías que responden más a la imagen "tradicional" del cuerpo de la mujer japonesa, con extremidades más pequeñas. A partir de este momento se comenzó a producir una imagen de la "mujer

\footnotetext{
${ }^{14}$ Kinoshita reconoce que el mercado de la fotografía en Japón evolucionó en Meiji, "pasando de una producción sistematizada centrada en retratos de señores feudales de diferentes dominios y samuráis, a una industria más dinámica y versátil abierta a un mayor público consumista” (Naoyuki, 2003; 17).
} 
japonesa" a partir del complejo proceso de hibridación cultural que se comenzaba a gestar entre Japón y Occidente.

En nüdo shashin se pueden distinguir cuatro tendencias estéticas predominantes en la forma en que se exhibe el cuerpo femenino: la primera tendencia imita la producción visual erótica occidental al introducir artefactos europeos dentro de las tomas y escenarios, así como nuevas poses y gestos corporales (Figura 5).

Figuras 5. Impresión albúmina de placa seca Tefudadai 135 x $91 \mathrm{~mm}$ 1887-1890 ca.

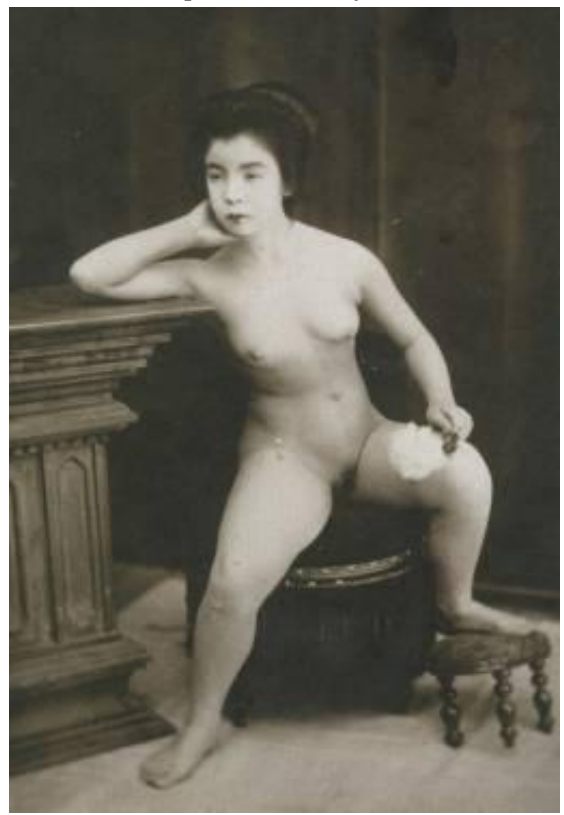

Fuente: Colección Ishiguro Keishō.

En cierta medida se podría decir que los fotógrafos que producían nūdo shashin copiaron el modelo de la fotografía erótica europea al asociar el cuerpo desnudo femenino como sinónimo de erotismo y como elemento de excitación sexual masculino, pero articulando este modelo de representación extranjero de manera tangencial con el proceso de domesticación del deseo sexual del hombre "moderno" y "civilizado" japonés. La segunda tendencia estética en nüdo shashin utiliza accesorios y espacios "tradicionales" donde el cuerpo de la mujer japonesa posa de manera "natural" junto con juegos de té o instrumentos que remiten al entretenimiento sexual femenino como el samisén (Figura 6).

La tercera tendencia estética adopta la forma idealizada de representar el desnudo femenino de la pintura estilo occidental producida por artistas yōga, y lo reformula incluyendo telones de fondo con paisajes pintados y rocas artificiales para simular ambientes "naturales" (Figura7). 
Figuras 6 y 7. Impresión albúmina de negativo en placa seca, carte de visite 85x55mm, 1887 ca.
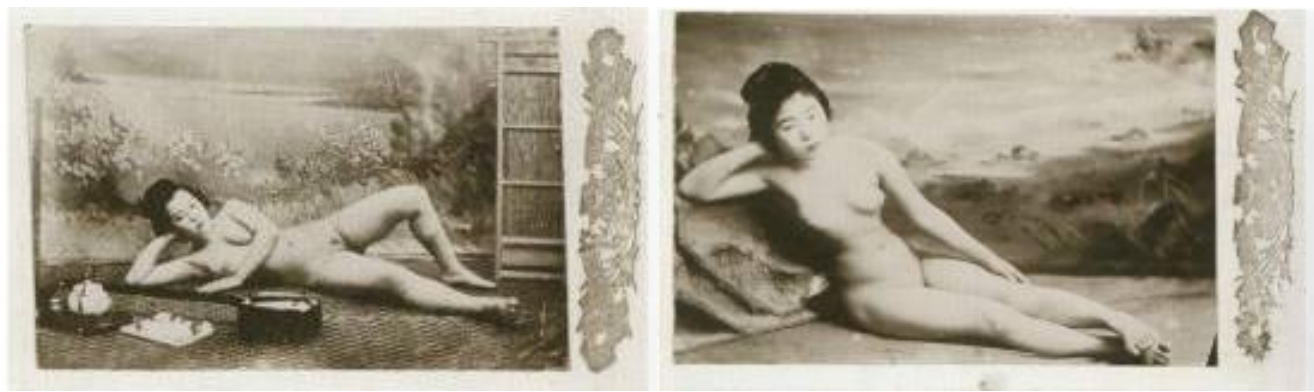

Fuente: Colección Ishiguro Keishō.

Las imágenes producidas por artistas yōga durante la década de 1880, definieron la ejecución del cuerpo femenino bajo los estándares estéticos occidentales. La obra de Yamamoto Hosui, Mujer desnuda (Rafu) de 1880 (Figura 8), y la de Hyakutake Kaneyuki, Desnudo Recostado (Hadaka ritsuzō) (Figura 9), producida en 1881(Bryson, 2003) son dos referentes iconográficos relevantes en la producción del desnudo femenino dentro de la pintura $y \overline{o g} a$, y de manera tangencial o indirecta, también van a repercutir en la manera de imaginar el cuerpo femenino en nüdo shashin.

Figura 8. Yamamoto Hosui, Mujer desnuda (Rafu), 1880.

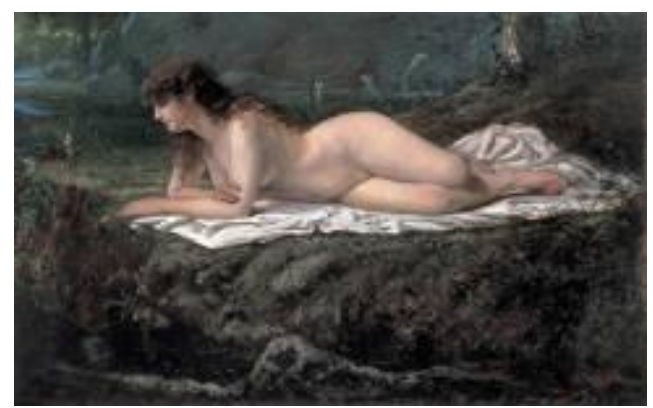

Fuente: Museo de Bellas Artes, Gifu, Japón.

Figura 9. Hyakutake Kaneyuki, Desnudo recostada (Hadaka ritsuzō), óleo sobre tela, 1881.

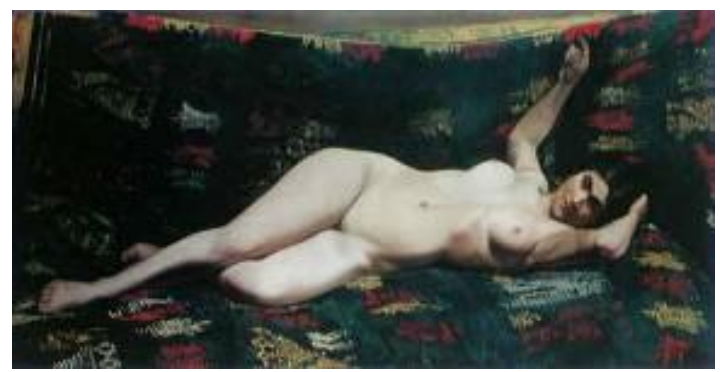

Fuente: Museo Prefectural de History de Kanagawa, Kanagawa, Japón. 
La cuarta tendencia estética dentro de nūdo shashin introduce elementos visuales e iconográficos de la estampa erótica japonesa shunga, especialmente el uso de kimonos como el referente visual más recurrente (Figura10). La vestimenta como elemento estético en la representación de escenas sexuales shunga tiene un papel relevante en la producción visual de lo sexual al formar parte de la mirada cultural del cuerpo erotizado en Japón.

Figura 10. Impresión albúmina de negativo en placa seca, carte de visite 55 x86mm, $1887 \mathrm{ca}$.

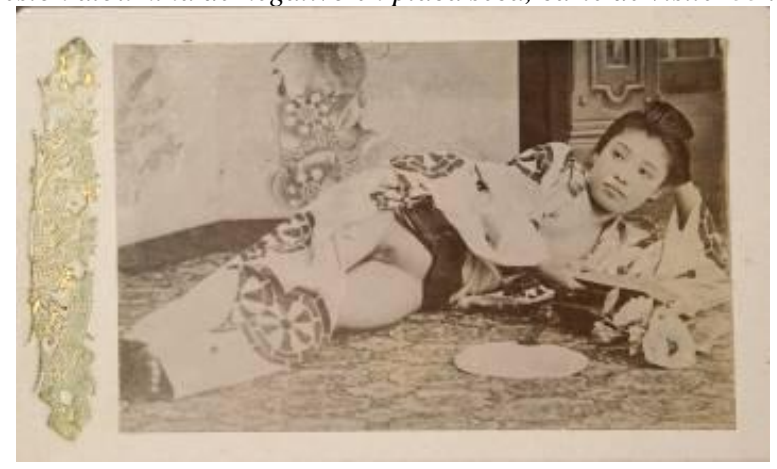

Fuente: Colección Ishiguro Keishō.

En otra impresión tamaño tefudadai o postal, una mujer se muestra con la tradicional misugami en la boca (Figura 11), ${ }^{15}$ un pañuelo que utilizaban las mujeres después de tener relaciones sexuales y que también era representado en impresiones shunga del Edo sostenido en la boca de las mujeres. En el contexto de nüdo shashin de Meiji, este elemento estético particular se refiere a la continuidad visual de las representaciones sexuales y las costumbres previas a la modernización. En otra imagen (Figura 12), dos mujeres cubiertas con kimonos se estimulan entre sí tocando sus genitales en una escena erótica que de nuevo nos remite a las escenas de shunga.

Entre la vasta producción de shunga durante el periodo Edo se representaban una amplia gama de conductas sexuales dentro de un ámbito muy amplio de consumo. Sin embargo, la apropiación iconográfica de shunga en nüdo shashin muestra estos elementos (el misugami, el kimono, futón, fusuma, etc) dentro de imaginarios visuales menos lujosos, extravagantes, e imaginativos, presentan imágenes sexuales en las que el coito entre hombres y mujeres es eliminado del campo visual, sustituidas por la sistemática exposición del cuerpo de la mujer japonesa, erotizado ya sea por sí misma o por otras mujeres.

\footnotetext{
${ }^{15}$ Misugami era un método contraceptivo usado frecuentemente entre las prostitutas durante el periodo Edo (1603-1868), pero, posteriormente fue adoptado como un método eficaz entre las mujeres comunes, ya que era un método práctico contra el embarazo. Misugami era un "papel hecho de fibra de bambú mojado con un aceite muy fuerte, el cual se metía dentro de la vagina para evitar el embarazo" (Keishō, 2002: 92).
} 
Figuras 11 y 12. Impresión colotipia, tefudadai 60x140, 1897 ca.
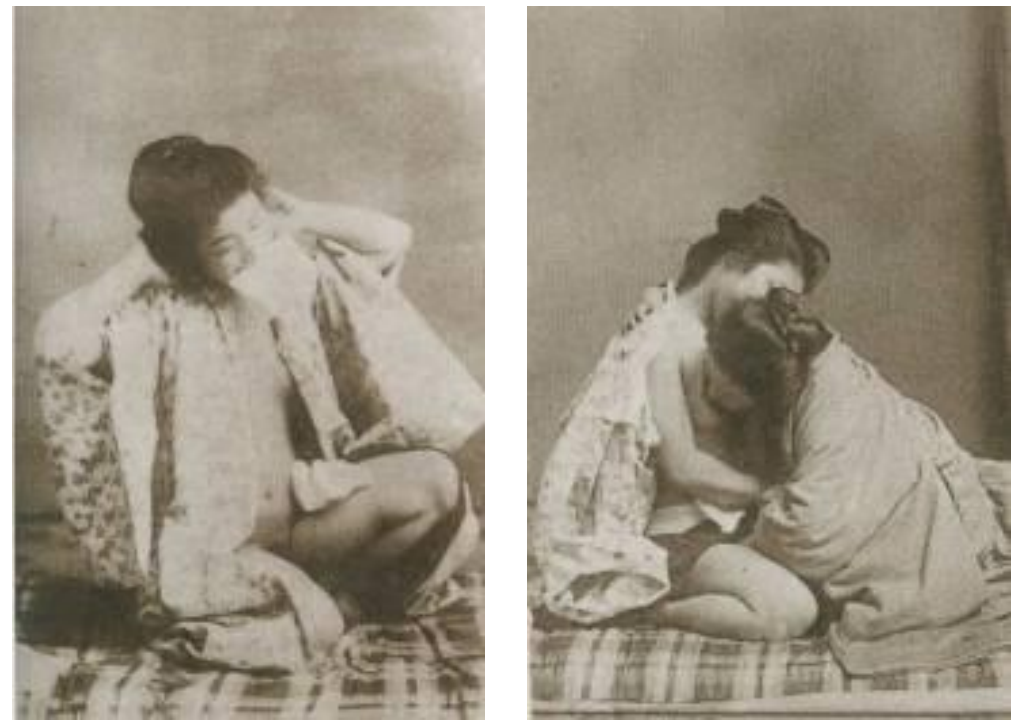

Fuente: Colección Ishiguro Keishō.

La risa en $n \bar{u} d o$ shashin es un elemento que genera más la sensación de comicidad que de erotismo. Durante mi entrevista con Ishiguro en Japón me mostró una imagen bastante peculiar de una mujer desnuda, parada y cruzada de manos riéndose (Figura 13), producida a finales del siglo XIX.

Figuras 13. Impresión albúmina de negativo en placa seca montada sobre cartón, 57x83mm, 1897 ca.
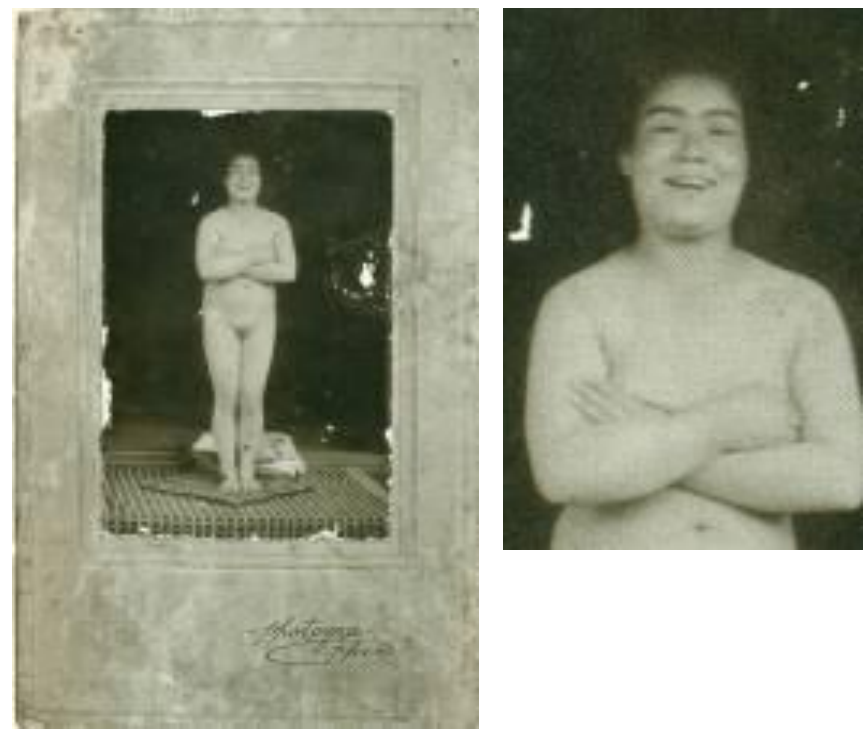

Fuente: Colección Ishiguro Keishō. 
Bajo la mirada del coleccionista esta imagen no la consideraba ni artística ni pornográfica, debido a que el cuerpo de esta mujer no le parecía atractivo o estéticamente bello. Sin embargo, podría observarse a partir del entrecruzamiaento entre el carácter cómico del retrato y la "naturaleza" supuestamente erótica que el desnudo femenino representará a partir de este momento en la fotografía del periodo Meiji.

En la última imagen seleccionada para este ensayo, una mujer posa con las piernas abiertas doblando sus piernas contrayéndolas hacia su torso centrando la atención en los genitales (Figura 14). Después de observar cuidadosamente la boca de la modelo se puede notar la faltan de higiene en su boca al mostrar los dientes parcialmente manchados, lo cual podría indicar la condición social de esta mujer.

Figuras 14. Impresión albúmina de negativo en placa seca, carte de visite 55x86mm, $1887 \mathrm{ca}$.

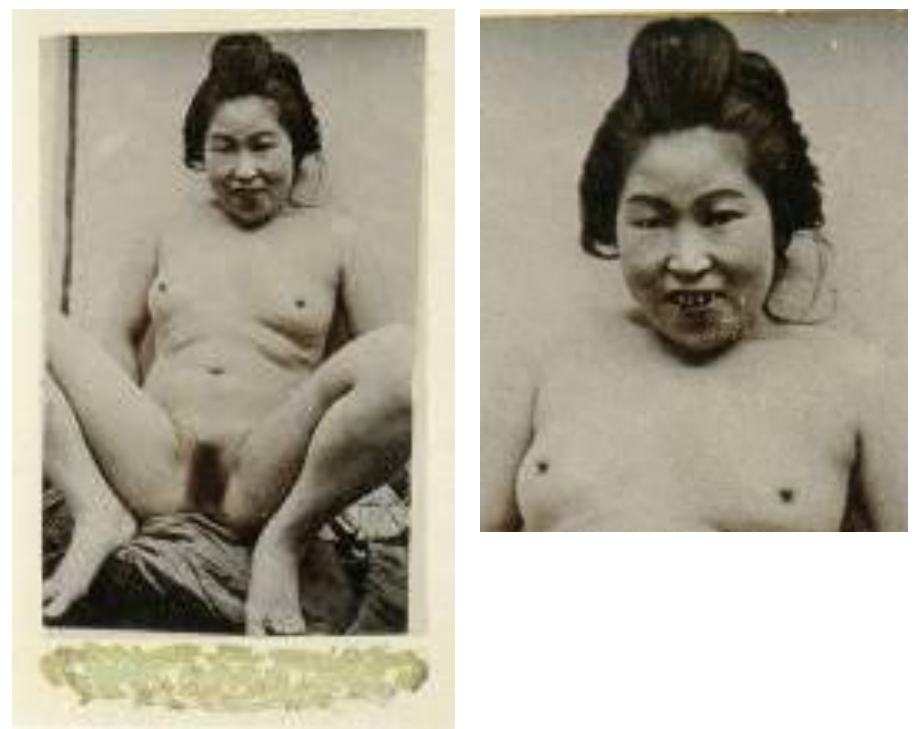

Fuente: Colección Ishiguro Keishō.

En esta fotografía la risa vuelve a ser un elemento que confronta nuestra mirada. Bajo las normas victorianas la risa era considerada como un acto de vulgaridad; sin embargo, la risa en nüdo shashin articula el sexo y el juego, una asociación que existía anteriormente en las representaciones sexuales, como en las estampas eróticas shunga (también llamadas warai-e).

El cuerpo femenino en $n \bar{u}$ do shashin es producido en un espacio simbólico donde el conocimiento científico en torno a la sexualidad moderna cobra sentido a partir de la distinción entre el cuerpo desnudo femenino, y el cuerpo invisible del hombre; uno concebido como espectáculo de transgresión sexual, el otro como sujeto deseante, heterosexual, e incorpóreo en el espacio de la representación, respondiendo a la nueva norma sexual civilizada de Meiji. De esta manera, estas imágenes pudieron funcionan 
como el espacio simbólico y visual donde se definió tanto la diferencia sexual, como al sujeto femenino transgresor, justo en un momento en el que el estado de "desnudez" y el "deseo sexual femenino" se transformaron en "tabú."

Durante el periodo de modernización, el cuerpo desnudo ante los ojos de la nueva nación japonesa fue declarado como un signo de la vergüenza y la exhibición pública del cuerpo desnudo fue prohibida después de la proclamación de la Ley de Delitos Menores contra la moral pública en 1872. Esta ley definía la exposición del cuerpo desnudo en el espacio público como un acto de barbarie, atraso, al replicar las normas morales victorianas. En conjunto, estas medidas represivas significaron un cambio radical en la redefinición tanto del cuerpo como del deseo sexual, femenino y masculino, ahora redefinido a través de la fuerza disciplinaria de la "obscenidad", introducido en Japón como waisetsu (Hibiki, 2008: 261). Como consecuencia, el cuerpo desnudo de la mujer se transformó en un objeto dañino que debe permanecer oculto en los márgenes de la sociedad, fuera de la escena (off-scene) real.

Mediante la inserción de $n \bar{u} d o$ shashin dentro de la lógica de la economía libidinal de Meiji, podemos empezar a considerar la re-formulación una cierta clase de "mujer japonesa," cuya influencia sobre las nociones modernas de la identidad sexual creció con el tráfico de tecnologías como la fotografía. De este modo, la visualización de la fotografía de desnudos femenino no sólo participó en la distinción sexual de género, también activó la posible relación inter-subjetiva entre la modelo, el fotógrafo, y el espectador por medio de la mirada, en la conformación de nuevos imaginarios visuales. Pero al final, mientras la exhibición de estas imágenes siga siendo un acto prohibido bajo una moral incongruente y contradictoria, el género fotográfico nūdo shashin se mantendrá marginal bajo el aura fantasmagórica del tabú sexual, recordando esta forma compleja de mirar el cuerpo femenino sólo como el producto de una modernidad desencantada, o como la sombra inquietante y decadente de una Venus.

\section{BIBLIOGRAFÍA}

- Bowman Jannetta, Ann (2007): The vaccinators: smallpox, medical knowledge, and the "opening" of Japan. Standford: Standford University Press.

- Bryson, Norman (2003): "Westernizing Bodies: Women, Art and Power in Meiji Yoga". En: Joshua S. Mostow; Norman Bryson y Meribeth Graybill (eds.): Gender and Power in the Japanese Visual Field. Honolulu: Hawaii University Press, pp. 89-118.

- Foucault, Michael (1998): Vigilar y Castigar. Nacimiento de la prisión. México: Editorial Siglo veintiuno editores. 
- García, Amaury (2011): El control de la estampa erótica japonesa shunga. El Colegio de México.

- Hibiki, Momose (2008): Bunmeikaika ushinawareta füzoku (Civilización e ilustración: los usos y costumbres perdidos). Tokio: Yoshikawa Kōbunkan.

- Hoshino, Chōichi, (1970): Meiji ratai shashincho. Hoshino Chōichi korekushon (Colección de fotografías de desnudos de Meiji. La colección de Hoshino Chōichi). Tokio: Arimitsu shobō.

- Kawai, Yū (2010): "Nūdo". En: Shōichi Inoue (ed). Seiteki na kotoba (Palabras sexuales). Tokio: Kōdansha, pp. 152-163.

- Keishō, Ishiguro (1996): Meijiki no porunogurafi (Pornografía de Meiji). Tokyo: Photo Museé, Shinchosha.

. (2002): Bikkuri nudo, omoshiro porno (Desnudos soprendentes, pornografía interesante).

Tokyo: Heibonsha.

- Kinoshita, Naoyuki (2003): “The early years of Japanese photography”. En: Anne Wilkes Tucker (ed.): The History of Japanese Photography. Houston: The Museum of Fine Arts, pp. 102-3. - Kobayashi , Fumiyo (2008): (M)othering the Empire?: A literary Study of Motherhood in Imperial Japan. Tesis Doctoral. University of Washington. The Department of Asian Languages and Literature.

- Kōshi, Shimokawa (1995): Nihon ero shashinshi (Historia de la fotografía erótica en Japòn). Tokyo: Seikyūsha.

- Lyotard, Francis (2004): The Libidinal Economy. New York:Continuum

- Marran, Christine L. (2007): The Poison Woman: Figuring the Female Transgression in Modern Japanese culture. Minneapolis: The University of Minnesota Press.

- March, Philipp y Delank, Claudia (2002): The Adventure of Japanese Photography 1860-1890. Heidelberg: The March Collection.

- Miho, Ogino (1990) (ed): Seido toshite no”onna” (“Mujer" como sistema). Tokio: Keinbonsha. . (2002): Jendaka sareru shintai (El cuerpo de género). Tokio: Keisō Shobō, pp. 164-96.

- O’brien, Suzanne (2007): "Diverting Desires and Audiences: Kabuki, Füzoku, and the State in Late Tokugawa Japan”. En: Studies on Asia, Illinois State University, Asian Studies Center, vol. 4, $\mathrm{n}^{\mathrm{o}}$ 1, pp. 1-16, [en línea] Disponible en: http://studiesonasia.illinoisstate.edu/seriesIII/vol4.shtml [12/01/2013].

- Ogi, Shinzō (1990): "Nihon fūzoku kairyōron”. En: Chizuko Ueno; Shinzō Ogi e Isao Kumakura (Eds). Sei/Fūzoku (Sexualidad/Costumbres). Tokyo: Iwanami Shoten

- Silver-Isenstadt, Jean L. (2002): Shameless: The visionary life of Mary Gove Nichols. Baltimore: The Johns Hopkins University Press.

- Reichert, Jim (2006): In the company of men: representations of male/male sexuality in Meiji. Stanford: Stanford University Press.

- Robinson, Bonnel D. (1988): "Transition and the quest for permanence: photographers and photographic technology in Japan, 1854-1880”. En: Melissa Banta y Susan Taylor, (eds.): A timely encounter: nineteenth century photographs of Japan. Cambridge, Massachusset: Peabody Museum Press, p. 39-51.

- Ueno, Chizuko; Ogi, Shinzō y Isao, Kumakura (1990) (eds): Sei/Fūzoku. (Sexualidad/Costumbres). Tokyo: Iwanami Shoten. 